\title{
DESIGN OF THE MAPPING OF ORANG UTAN WITH SPATIAL DATA APPROACH TO WEB-BASED GEOGRAPHIC INFORMATION SYSTEMS
}

\author{
Jadiaman Parhusip $^{\text {a,1,*}}$, Rony Teguh ${ }^{\text {b,2 }}$, Liyando Hermawan Hasibuan ${ }^{\text {c,3 }}$ \\ ${ }^{a}$ Universitas Palangka Raya, Jl. H. Timang \\ ${ }^{\mathrm{b}}$ Universitas Palangka Raya, Jl. H. Timang \\ ${ }^{\text {c }}$ Universitas Palangka Raya, Jl. H. Timang \\ ${ }^{1}$ parhusip.jadiaman@it.upr.ac.id *; ${ }_{2}$ ronyteguh@it.upr.ac.id ; ${ }^{3}$ liyandohermawan@ict.upr.ac.id \\ * corresponding author
}

ARTICLE INFO

Keywords

GIS

Website

Orangutan

Mapping

W2000

\section{ABSTRACT}

Orangutans are the only great apes that live in Asia and have the most threatened status in the world. Currently there are three types of orangutans in Indonesia; the Sumatran orangutan (Pongo abelii), the Borneo orangutan (Pongo pygmaeus) and the Tapanuli orangutan (Pongo tapanuliensi). The types of colors that enter critical status are endangered (critical) based on International Unity for Nature Conservation in 2017. Approximately $75 \%$ of the distribution of orangutans will be outside the sexuality area need data distribution and orangutan population to meet data needs for the benefit of orangutans. This study used a method to collect data which were of library studies, data retrieval, consultation and discussion studies. After the data was collected, it was conducted need analysis and system design using the W2000 Software Development Method, which included process design, database design, menu structure design and interface design. Then the system implementation utilized Google Map Service and the PHP programming language based on the website with the MYSQL database. The results of the testing are several locations of orangutan nests where every point owns information in the form of the number of orangutans and their population. The results of this study are the mapping of orangutan's nests with a GIS web-based spatial data approach that will provide information on nest position, nest density, orangutan population density which is at the position of the nest radius.

\section{Pendahuluan}

\subsection{Latar Belakang}

Berdasarkan hasil Population and Habitat Viability Assessment (PHVA) Orangutan 2016, saat ini diperkirakan terdapat 71.820 individu Orangutan di Pulau Sumatera dan Borneo (Kalimantan, Sabah dan Serawak) yang seluruhnya tersebar pada pada habitat seluas 17,46 juta hektare. Dari total tersebut, hanya 38\% di antaranya yang diprediksi akan lestari atau viable dalam 100 sampai 150 tahun ke depan.

Semua sub-spesies orangutan Borneo adalah spesies langka dan sepenuhnya dilindungi oleh perundang-undangan Indonesia. Spesies ini diklasifikasikan oleh CITES ke dalam kategori Appendix I (spesies yang dilarang untuk perdaganan komersial internasional karena sangat rentan terhadap kepunahan). Beberapa ancaman utama yang dihadapi oleh orangutan Borneo adalah kehilangan habitat, pembalakan liar, kebakaran hutan, perburuan dan perdagangan orangutan untuk menjadi satwa peliharaan. Dalam satu dekade terakhir, di tiap tahunnya, paling tidak terdapat 1,2 
juta ha kawasan hutan di Indonesia telah digunakan untuk aktivitas-aktivitas penebangan berskala besar, pembalakan liar, serta konversi hutan untuk pertanian, perkebunan, pertambangan, dan pemukiman. Kebakaran hutan yang disebabkan oleh fenomena iklim seperti badai El Nino dan musim kering yang berkepanjangan juga mengakibatkan berkurangnya populasi orangutan. Selama 20 tahun terakhir, habitat orangutan Borneo berkurang paling tidak sekitar 55\% Laporan Population and Habitat Viability Assessment (PHVA) tahun 2004.

Dilapangan perlindungan orang utan sendiri memiliki berbagai macam kendala yang sangat terbatas. Mulai dari biaya sampai dengan waktu sementara dari hari ke hari spesies orangutan menjadi lebih sedikit. Kebutuhan akan informasi dari beberapa sarang orang utan di habitat liar turut menjadi agenda wajib dan di data secara teratur. Perubahan data serta pembaruan informasi seharusnya menjadi lebih cepat sehingga untuk itu dibutuhkan akses informasi yang dapat menghimpun data secara besar dan bisa diakses lebih mudah.

\subsection{Perumusan Masalah}

Bagaimana membuat "Rancang Bangun Pemetaan sarang orang utan dengan pendekatan spasial data berbasis website GIS"?

\subsection{Komponen Sistem Informasi}

Sistem informasi terdiri dari komponen-komponen yang disebut blok bangunan (building block), yang terdiri dari komponen input, komponen model komponen output, komponen teknologi, komponen hardware, komponen software, komponen basis data, dan komponen kontrol. Semua komponen tersebut saling berinteraksi satu dengan yang lain membentuk suatu kesatuan untuk mencapai sasaran. Mahamudu [1], Lipursari [2], Anggadini [3], Warman [4].

\subsection{Sistem Informasi Geografis}

Sistem Informasi Geografis merupakan sistem berbasis komputer yang biasanya digunakan untuk menyimpan, memanipulasi, dan menganalisa informasi geografis. Sebelum adanya Sistem Informasi Geografis ini, sejumlah informasi permukaan bumi disajikan dalam peta yang dibuat secara manual. Hadirnya SIG dapat mengolah komponen peta tersebut dalam komputer, kemudian hasilnya berupa peta digital. SIG dapat menggabungkan berbagai jenis data pada satu titik tertentu yang ada di bumi, menghubungkannya, menganalisanya, hingga memetakan hasilnya. Data yang diolah oleh sistem ini adalah data spasial yakni data yang berorientasi pada geografis. Selain itu juga merupakan lokasi yang mempunyai koordinat tertentu. Hal tersebut sebagai dasar referensi analisa dan pemetaan hasilnya. Karena itu, aplikasi SIG ini dapat menjawab beberapa pertanyaan tentang geografis bumi seperti lokasi, kondisi, pola, pemodelan, serta tren. Kemampuan ini yang membedakan SIG dengan sistem informasi lainnya. SIG sendiri dikenalkan di Indonesia pada 1972 dengan nama Data Banks for Development. Munculnya istilah Sistem Informasi Geografis atau Geographic Information System sendiri setelah dicetuskan oleh General Assembly dari International Geographical Union di Ottawa, Kanada pada 1967 (Ilmu Geogragrafi.com Maret 2018). Beberapa penelitian untuk berbagai keperluan telah dikembangkan selama ini dengan Sistem Informasi Geografis. Yakin dan Musthafa [5] telah membuat Rancang Bangun SIG berbasis web untuk memantau kualitas SLTP di Kabupaten Gresik. Jadiaman Parhusip, Widiatry, dan Esra [6] telah mengembangkan SIG berbasis multimedia untuk bidang transportasi di Kalimantan Tengah. Siti Suryani, dkk [7], dengan Sistem Informasi Geografis Pemetaan Sekolah Tingkat Pendidikan Dasar Dan Menengah Di Kota Serang. Andika [8] dengan gambaran spasial kasus demam tifoid dengan metode GIS (Geographic Information System) di Kecamatan Panakkukang Kota Makassar. Ansariadi dan Alimunddin [9] dengan Spatial Analysis For Several Important Diseases and Health Service In South Sulawesi; Experiences Using GIS Methodes In Health. Ari dan Porkab [10] dengan Panduan Sarang Orangutan. Sylvia, dkk [11] dengan Aplikasi Sistem Informasi Geografis (SIG) Untuk Pemetaan Pasar Tradisional Di Kota Semarang Berbasis 
Web. Kunang dan Sulaiman [12] dengan Sistem Informasi Geografis Pemetaan Populasi Hewan Ternak Di Sumatera Selatan Berbasis Web. Lestari, dkk [13] dengan Sistem Informasi Geografis (SIG) Daerah Rawan Banjir Di Kota Bengkulu Menggunakan Arcview. Maharani, dkk. [14] dengan Sistem Informasi Geografis Pemetaan Masjid Di Samarinda Berbasis Web. Fernando [15] dengan Sistem Informasi Geografis Untuk Pemetaan Tempat Kesehatan di Kota Jambi.

\section{Metode Penelitian}

Metode Penelitian yang dipakai dalam pembuatan "Sistem Informasi Pemetaan Sarang Orang Utan Dengan Pendekatan Spasial Data Berbasis Website GIS" yaitu:

1) Metode Pengumpulan data

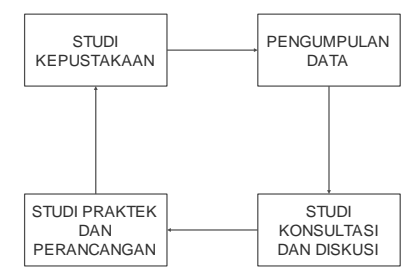

Gambar 1. Metode Penelitian

Metode penelitian untuk membuat "Sistem Informasi Pemetaan sarang orang utan dengan pendekatan spasial data berbasis website GIS", yaitu meliputi :

a. Studi kepustakaan, literatur, referensi seperti mempelajari buku dan informasi dari internet yang berhubungan dengan proses pembuatan aplikasi. Melakukan pengamatan terhadap berbagai aplikasi sejenis untuk melengkapi fitur aplikasi ini.

b. Metode pengumpulan data, merupakan tahap pengambilan data atau sampel yang berhubungan dengan perma-salahan yang sedang dibahas. Dalam pengumpulan data tersebut menggunakan teknik-teknik pengumpulan data, yaitu observasi. Observasi merupakan peninjauan langsung ke tempat instansi yang diteliti, yaitu Organisasi "World Wide Fund for Nature (WWF)" sehingga mendapatkan data yang aktual dari hasil penelitian yang dilakukan.

c. Studi konsultasi dan diskusi yaitu berupa tanya jawab dengan orang-orang yang berhubungan dengan penelitian orang utan.

2) Metode Pengembangan Perangkat Lunak

Metode Pengembangan yang digunakan adalah metode Pengem-bangan W2000. Dimana tahapan utama terlebih dahulu menganalisa kebutuhan mulai dari kebutuhan fungsional dan kebutuhan navigational. tahap kedua melakukan desain hypermedia dan tahap terakhir melakukan desain fungsional dan testing dilakukan di sini.

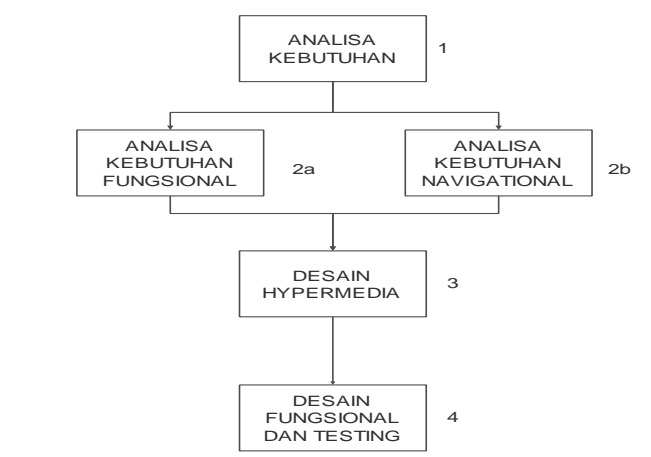

Gambar 2. Diagram Alur Metodologi W2000 [16] 


\section{JURNAL TEKNOLOGI INFORMASI}

[E-ISSN 2656-0321]

[Vol. 12 No. 2]

Jurnal Keilmutan dan Aplikasi Bithang Teknik Informatika

[Agustus 2018]

1. Analisis Kebutuhan

Mengumpulkan kebutuhan secara lengkap, kemudian dianalisis. Didefinisikan kebutuhan yang harus dipenuhi oleh website yang akan dibangun. Fase ini harus dikerjakan secara lengkap untuk bisa menghasilkan desain yang lengkap. Layanan, batasan, dan tujuan sistem ditentukan melalui konsultasi dengan user sistem yaitu Organisasi WWF sendiri serta menentukan beberapa bagian pokok.

a. Analisis Kebutuhan Fungsional

Kebutuhan fungsional adalah jenis kebutuhan yang berisikan proses-proses apa saja yang diberikan oleh sistem. Dimana sistem ini dapat digunakan oleh pengguna yaitu operator/karyawan dan administrator/ pemilik dimana pengamat atau pemilik memiliki hak akses yang berbeda didalam sistem tersebut, berikut yang akan dijalankan sistem. Di dalam ini terdapat definisi Use Case dan Use Case dari Sistem Informasi Pemetaan sarang orang utan dengan pendekatan spasial data berbasis website GIS.

b. Analisis Kebutuhan Navigational

Kebutuhan navigational adalah jenis kebutuhan yang berisikan rincian dari navigasi serta penerapan pada program yang dibuat di dalam program ini Activity Diagram dan Squence Diagram akan dimasukkan.

\section{Desain Hypermedia}

Desain Hyprermedia adalah desain yang berisi desain rancangan dimana melibatkan proses antar laman biasanya di dalam program Navigasi Link dan Template akan di gunakan sebagai bagian dari Desain Hypermedia.

3. Desain Fungsional dan Testing

Desain Fungsional adalah desain yang berisi fungsi-fungsi yang menghubungkan antar laman. Ada juga fungsi penyimpanan, Desain Fungsional digambarkan dengan Class Diagram dan Database lalu melakukan Testing didalamnya.

\section{Hasil Dan Pembahasan}

3.1 Flowchart Pengamat 


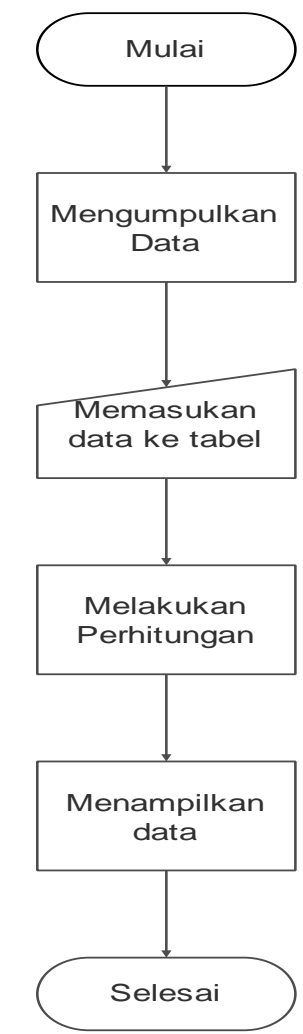

Gambar 3. Flowchart Pengamat

1) Way Point Transek (titik kordinat)

7 data di atas diharapakan dapat memberikan posisi kordinat yang sesuai dimana pengguna $\mathrm{X}$ (longitude) dan Y (latitude) posisi tersebut akan di sesuaikan pada layer yang ada.

2) Kepadatan Sarang Orangutan

Di dalam Panduan sarang Orangutan kepadatan sarang mengacu pada rumus

$$
\begin{aligned}
\mathrm{N} & =23 \\
\mathrm{I} & =1000 \mathrm{~m}, 1 \mathrm{~km}
\end{aligned}
$$

$\mathrm{w}=0,020003$ (ketetapan Lebar jalur efektif Kalteng)

$$
D(N)=\frac{\sum N}{\mathrm{l} .2 \mathrm{w}}
$$

Mengacu pada rumus yang ada dengan menggunakan data ID transek yang ada maka

$\mathrm{D}(\mathrm{N})=23 / 1 \times 2(0,020003)$

$$
=575 \mathrm{~N} / \mathrm{km}^{2}
$$

3) Kepadatan Orangutan

Menghitung kepadatan orang utan menggunakan rumus

$$
\begin{array}{ll}
\mathrm{D}(\mathrm{N}) & =12,5 \mathrm{~N} / \mathrm{km}^{2} \\
\mathrm{p} & =0,9 \\
\mathrm{r} & =1,16 \\
\mathrm{t} & =297 \\
\mathrm{D}(\mathrm{OU}) & =12,5 / 0,9 * 1,16^{*} 297 \\
& =\mathbf{1 , 8 5 4} \mathbf{O U} / \mathbf{k m}^{2}
\end{array}
$$

$$
D(O U)=\frac{D(N)}{p \cdot r \cdot t}
$$

4) Menghitung Populasi orang utan 
Populasi oranghutan menggunakan rumus $\mathrm{D}(\mathrm{OU})^{*}$ jumlah hutan yang ada. Pada tahun 2010 Jumlah hutan yang ada di dalam satu area yakni dengan asumsi $60 \mathrm{~km}^{2}$.

Populasi $=1,854 * 60$

$$
\text { = } 111 \text { Orangutan }
$$

3.2 Analisis Kebutuhan Navigational

A. Kebutuhan dari Administrator

1. Kelola Akun

2. Kolola Tempat

3. Kelola Galeri

4. Kelola Password

B. Kebutuhan dari Pengamat

1. Kelola Peta

2. Kelola Data Pengamat

\subsection{Class Diagram Sistem}

Class diagram (Gambar 4) menggambarkan struktur dan deskripsi class, package dan objek besera hubungan satu sama lain. Pemodelan dalam pembuatan Class Diagram yaitu menentukan kelas, atribut dan hubungan antar kelas, pada tahap ini belum menentukan method(fungsi) karena akan dilakukan pada tahap desain. Salah satu cara penentuan kelas adalah mencari kandidat kelas yang berasal dari use case.

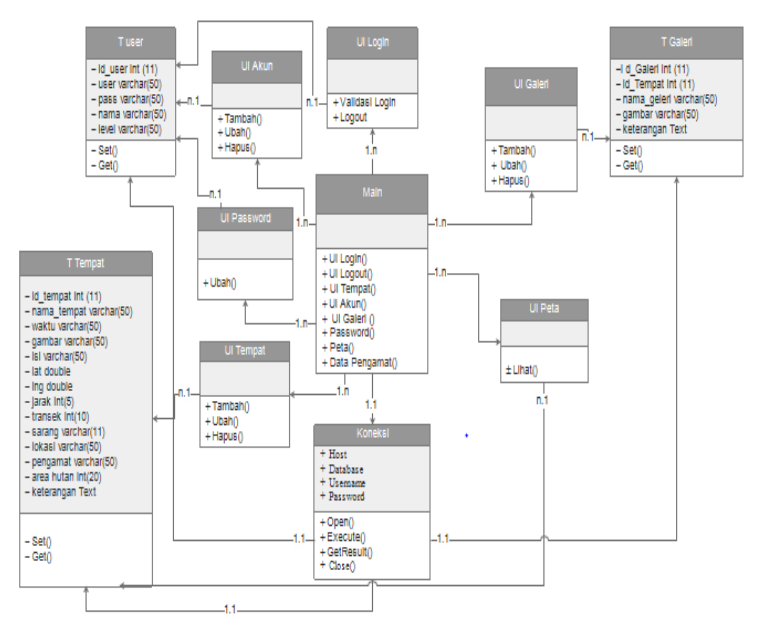

Gambar 4. Class Diagram Sistem

3.4 Use Case Pemetaan Sarang Orang Utan 


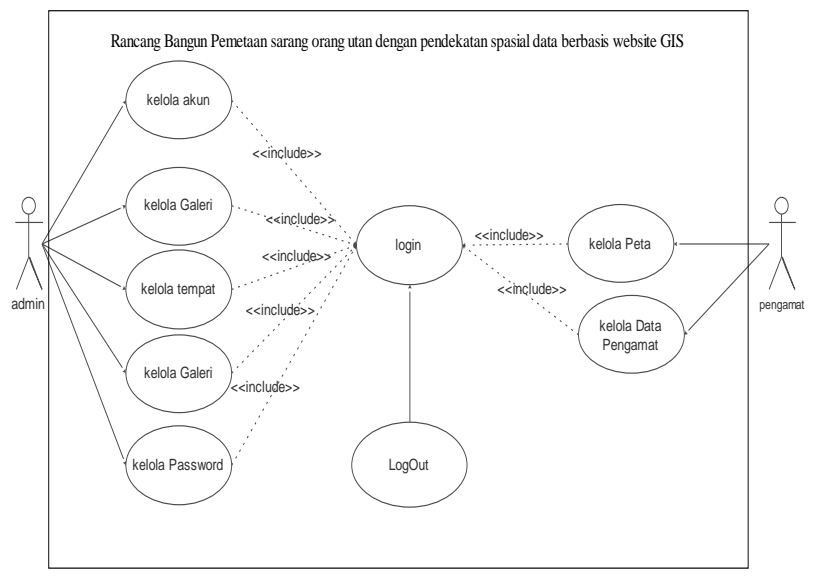

Gambar 5. Use Case Pemetaan Sarang orangutan

\subsection{Desain Hypermedia}

\subsubsection{Navigation Class}

1. Admin

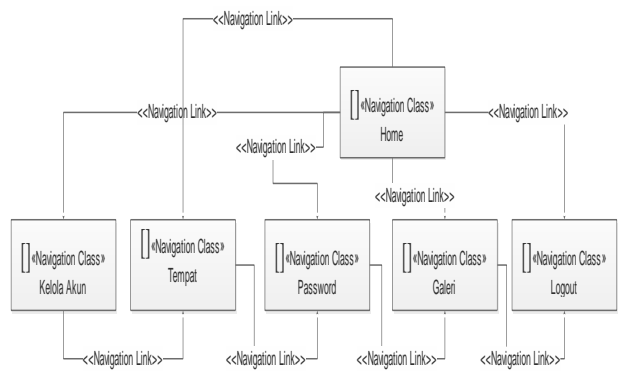

Gambar 6. Navigation Class Admin

2. Pengamat

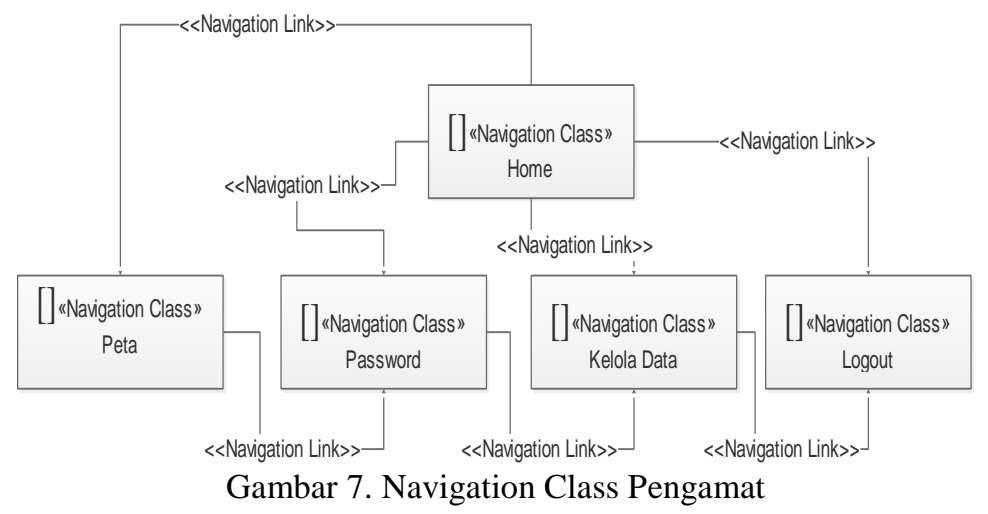

3.5 Desain Fungsional

1. Way Point Transek (titik koordinat)

Titik Kordinat di dalam website yang telah di bangun menggunakan Fungsi POST dari PHP itu sendiri untuk mengirim ke dalam database kemundian menggunakan Perinta SQL untuk melakukan pemanggilan ke bagian depan.

2. Kepadatan Sarang 


\section{JURNAL TEKNOLOGI INFORMASI}

[E-ISSN 2656-0321]

[Vol. 12 No. 2]

Jurnal Keeilmutan dann Aplikasi Bidang Teknik Informaiika

[Agustus 2018]

Kepadatan Sarang Orang utan menggunakan rumus dalam bentuk PHP dimana di dalamnya variable dari ketetapan tidak di masukan ke dalam database tapi berada pada script PHP

3. Kepadatan Orangutan

Kepadatan Orangutan menggunakan rumus dalam bentuk PHP dimana di dalamnya variable dari ketetapan tidak di masukan ke dalam database tapi berada pada script PHP

4. Populasi Orangutan

Populasi Orang utan menggunakan rumus dalam bentuk PHP dimana di dalamnya variable dari ketetapan tidak di masukan ke dalam database tapi berada pada script PHP

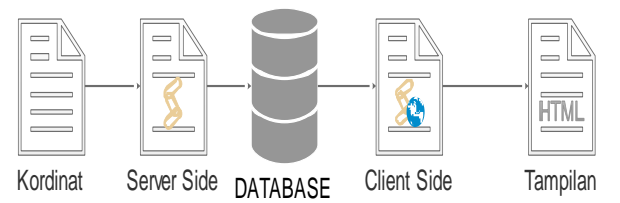

Gambar 8. Way Point Transek Proses

\subsection{Implementasi Antar Muka}

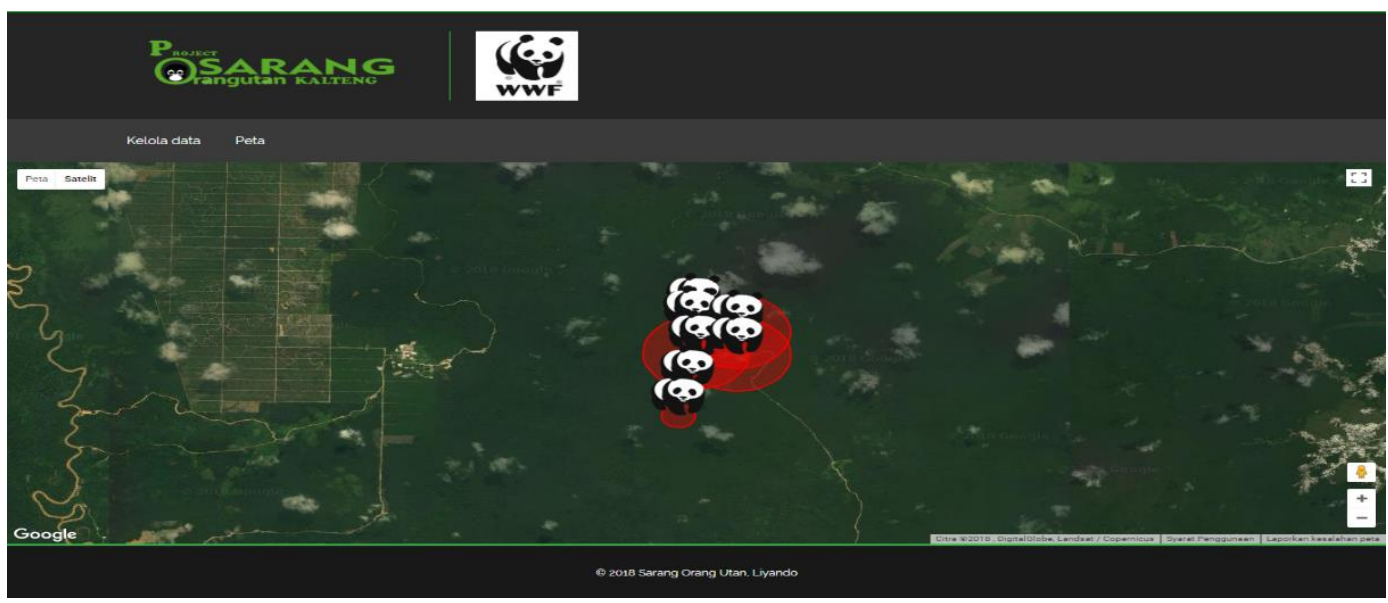

Gambar 9. Halaman Peta 


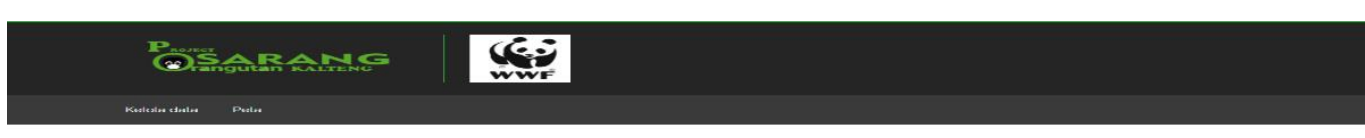

Lokasi orang utan 4

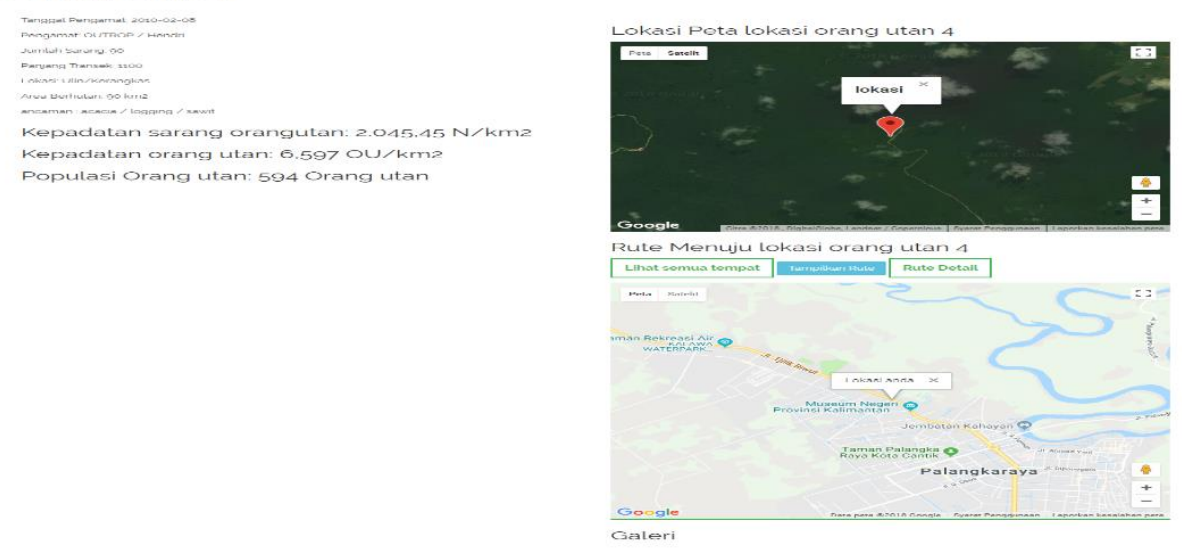

Gambar 10. Halaman Lokasi Orang Utan

\section{Kesimpulan Dan Saran}

\subsection{Kesimpulan}

Dalam "Rancang Bangun Pemetaan sarang orang utan dengan pendekatan spasial data berbasis website GIS" di dapat kesimpulan sebagai berikut. Dalam satu kordinat terdapat banyak sarang orangutan dimana setiap sarang memiliki jumlah populasi orang utan yang berbeda-beda. Dengan data yang di dapat dapat memberikan 4 hasil yaitu posisi sarang orangutan, kepadatan sarang orangutan, kepadatan orangutan dan populasi orang utan. Ditambah dengan Fungsi Populasi Dugaan Menghasilkan Hitungan secara akurat.

\subsection{Saran}

Saran dalam "Rancang Bangun Pemetaan sarang orang utan dengan pendekatan spasial data berbasis website GIS" di dapat sebagai berikut. Penambahan data ke depannya seyogyanya dapat mengumpulkan berbagai macam tingkah laku dari orangutan sehingga dalam hal ekologi serta perpindahan dapat dihitung untuk memudahkan para pengamat menentukan jalur yang efektif dalam memberikan pengamatan. Ekosistem yang ada juga dapat dimuat di dalam GIS dengan mengumpulkan data melewati satelit atau melalui penelitian langsung ke lapangan.

\section{Daftar Pustaka}

[1] Mahamudu, Billy N., 2012. Komponen Sistem Informasi. http://apr11- si.comuf.com/komponen.php

[2] Lipursari, Anastasia. 2013. Peran Sistem Infomasi Manajemen (SIM) Dalam Pengambilan Keputusan. Jurnal STIE Semarang, Vol. 5, No. 1, Edisi Februari 2013 (ISSN:2252-7826) https://media.neliti.com

[3] Anggadini, Sri Devi. Tanpa Tahun. Analisis Sistim Informasi Manajemen Berbasis Komputer Dalam Proses Pengambilan Keputusan. Majalah Ilmiah UNIKOM Vol. 11, No. 2 https://jurnal.unikom.ac.id

[4] Warman, Indra. 2012. Sistem Informasi Alumni ITP Menggunakan PHP dan MySQL https://ejournal.itp.ac.id 
[5] M. Ainul Yakin dan Muhammad Bisri Musthafa. 2013. Rancang Bangun Sistem Informasi Geografis (SIG) Berbasis Web Untuk Memantau Kualitas SLTP Di Kabupaten Gresik, Seminar Nasional Matematika dan Aplikasinya 2013, Universitas Islam Negeri Maulana Malik Ibrahim, Malang

[6] Jadiaman Parhusip, Widiatry, dan Esra Anggraini. 2012. Sistem Informasi Geografis Transportasi Kalimantan Tengah Berbasis Multimedia Menggunakan WAMP. SemnasIF 2012, UPN "Veteran" Yogyakarta, 30 Juni 2012 ISSN:1979-2328

[7] Siti Suryani, Priyo Sidik Sasongko, dan Edy Suharto, 2015. Sistem Informasi Geografis Pemetaan Sekolah Tingkat Pendidikan Dasar Dan Menengah Di Kota Serang, Univ. Diponegoro, DOI: 10.14710/jmasif.2.3.39-50

[8] Andika. 2010. Gambaran Spasial Kasus Demam Tifoid Dengan Metode GIS (Geographic Information System) di Kecamatan Panakkukang Kota Makassar. Tahun 2009. Skripsi tidak dipublikasikan. Fakultas Kesehatan Masyarakat Universitas Hasanuddin

[9] Ansariadi dan Alimunddin, 2009. Spatial Analysis For Several Important Diseases and Health Service In South Sulawesi; Experiences Using GIS Methodes In Health. Australia: Charles Darwin University Press.

[10] Meididit Ari dan Pratama Muhammad Porkab. 2017 Panduan Sarang Orangutan

[11] Sylvia Tri Yuliani, Bambang Sudarsono, Arwan Putra Wijaya, Bambang Sudarsono, dan Arwan Putra Wijaya. 2016. Aplikasi Sistem Informasi Geografis (SIG) Untuk Pemetaan Pasar Tradisional Di Kota Semarang Berbasis Web (2016), Jurnal GEODESI UNDIP April

[12] Suzi Oktavia Kunang, dan Sulaiman. 2016. Sistem Informasi Geografis Pemetaan Populasi Hewan Ternak Di Sumatera Selatan Berbasis Web, Jurnal Ilmiah Matrik, April, ArcGIS web gis

[13] Rahma Wayan Lestari, Indra Kanedi, Yode Arliando. 2016. Sistem Informasi Geografis (SIG) Daerah Rawan Banjir Di Kota Bengkulu Menggunakan Arcview, Jurnal Media Infotama Vol. 12 No. 1, Februari 2016

[14] Septya Maharani, Dina Apriani, Awang Harsa Kridalaksana, Sistem Informasi Geografis Pemetaan Masjid Di Samarinda Berbasis Web, Jurnal Informatika Vol. 11. No. 1, Jan 2017, Program Studi Ilmu Komputer Universitas Mulawarman

[15] Erick Fernando, 2012. Sistem Informasi Geografis Untuk Pemetaan Tempat Kesehatan di Kota Jambi. Seminar Nasional Ilmu Komputer Universitas Diponegoro, At Semarang - Indonesia, Volume: ISBN 978-979-756-841-2 DOI: 10.13140/RG.2.1.1476.0405

[16] Simarmata, Janner. 2010. Rekayasa Web. Edisi Pertama. Penerbit ANDI. Yogyakarta 